\title{
Understanding perceptions of recovery from psychological distress in Sierra Leone through qualitative comparative analysis
}

\author{
Kanykey Jailobaeva (10 ${ }^{1 凶}$, Rebecca Horn (10 ${ }^{1}$, Abdulai Jawo Bah², Giulia Loffreda ${ }^{1}$ \& Alastair Ager ${ }^{1}$
}

Qualitative comparative analysis (QCA) is a relatively new method that examines causal complexity. Its use in mental health research is nascent. In low-income and fragile settings, with weak mental health service provision, identifying pathways of recovery from psychological distress can inform the appropriate deployment of scarce community and public resources. This paper examines the use of QCA to identify predictors of recovery in Sierra Leone. Our study explored lay perceptions of the signs of recovery from psychological distress caused by such events as the loss of a family member, severe sickness, and loss of a relationship. The data drew upon 75 interviews with women and men, across four districts of Sierra Leone, who described the signs of recovery from psychological distress they have observed in one person known to them. The truth table generated through QCA software indicated two signs of recovery - work/study and healthy relations-to be the most prevalent across different combinations of predictive factors. Further analysis of the truth table and sub-set relations suggested that work/study and healthy relations frequently served as sufficient conditions for reported recovery from distress to occur. QCA provided a means to identify sufficient predictive factors for recovery from psychological distress to occur. The findings suggest that to enable recovery from psychological distress, support needs to be broad and bring together services that will enable individuals to improve their social and relational wellbeing. Responses to distress need to involve a wide range of community-based stakeholders who will help individuals to engage in constructive activity and strengthen relations with their family members, friends, and the broader community. QCA is potentially well-positioned to unpack complexity in mental health research.

\footnotetext{
${ }^{1}$ Institute for Global Health and Development, NIHR Global Health Research Unit on Health in Situations of Fragility, Queen Margaret University, Musselburg, UK. ${ }^{2}$ College of Medicine and Allied Health Sciences, Sierra Leone Institute for Global Health and Development, NIHR Global Health Research Unit on Health in Situations of Fragility, Queen Margaret University, Musselburg, UK. ${ }^{凶}$ email: kjailobaeva@qmu.ac.uk
} 


\section{Background}

$\mathrm{n}$ the past few decades, a recovery model has been increasingly used in community mental health services. The model looks beyond symptom management by providing service users with tools for recovery (Compton et al., 2020) and enabling individuals with mental illness to have satisfying and meaningful lives in the community (Kerman et al., 2019). Despite the World Health Organization's (WHO's) advocacy of a recovery-based approach (Sorensen et al., 2017), this has rarely been used in low-income and middle-income countries (LMICs) (Pahwa et al., 2020), where mental health services are limited and continue to be heavily focused on the institutionalization of individuals with mental illness. Lack of public awareness and resources are among the factors explaining the poor state of mental health services in LMICs (Patel et al., 2018a). Meanwhile, more than $80 \%$ of people experiencing mental disorders and substance abuse live in LMICs (Patel and Prince, 2010). Research on recovery from mental health issues in LMICs is scarce (Sorensen et al., 2017).

Alongside the shift towards a recovery model, there has also been a greater focus on local priorities, strengthening community resources and developing endogenous solutions to mental health issues (Kirmayer and Pedersen, 2014). Individuals affected by mental health problems are part of a web of connections within which the process of recovery occurs, contextualized by cultural diversity and social determinants of health. The community that the individual is embedded within can facilitate the process of recovery (Onken et al., 2007), or can hinder it through stigmatizing and discriminatory practices which contribute to social exclusion (Dinos et al., 2004; Thornicroft, 2013; Patel et al., 2018b).

Community mental health competence (CMHC) means that people collectively are able to participate in promotion, prevention, responses to mental health issues and advocacy (Mathias, 2016), which can improve the lives of people living with mental distress. Mathias et al. (2018) found that increased knowledge and awareness of mental health issues in a North Indian community, in combination with the development of reflective listening and respectful communication skills, led to increased social inclusion of those experiencing psychological distress. The recent Lancet Commission on Global Mental Health (Patel et al., 2018a) cites emerging evidence of reductions in stigmatization of people with mental health problems in LMICs through culturally adapted interpersonal contact interventions. Engaging with the social context is essential for building community mental health, and this requires an understanding of current beliefs within communities relating to distress, including patterns of recovery.

Sierra Leone is a low-income country in Western Africa. It has a population of over seven million people (Sierra Leone Statistics, 2016) and faces an array of development challenges, including poor governance, unemployment, and limited resources (World Bank, 2019). It has also experienced several crises, including a civil war between 1991 and 2002 (Stewart et al., 2016), an Ebola outbreak in 2014 (Yadav and Rawal, 2015), and a natural disaster that resulted in mudslides and flooding in 2017 (Harris et al., 2018).

These crises have significantly affected the infrastructure of the country, including mental health services (McPake et al., 2019). There is one psychiatric hospital that receives referrals from provincial and district hospitals (Harris et al., 2020). Recent analysis has highlighted the implausibility of addressing mental health needs through the strengthening of the health care workforce in Sierra Leone. McPake and colleagues (2019) have projected that a ten-fold increase in the national workforce is required to achieve even the modest goal of matching neighbouring Guinea in having 1.12 health workers per 1000 population. This is well below the international benchmarks of 2.5 per
1000 , or 4.45 per 1000 for universal health coverage. Communitybased approaches-which focus on strengthening the ability of informal helpers to provide effective social and emotional support, as well as referring people for different types of help-may therefore be particularly useful in Sierra Leone.

Mental health research in Sierra Leone has predominantly focused on the consequences of extreme events-particularly the civil war and the Ebola outbreak-on the psychological wellbeing of various groups in the population, such as child soldiers (Betancourt et al., 2011, 2013; Song et al., 2013), Ebola survivors (Lee-Kwan et al., 2014; Scott et al., 2016), and war victims (Gupta and Zimmer, 2008; Miller and Rasmussen, 2014; Newnham et al., 2015). Little is known about psychological distress in the general adult population, or community perceptions of distress and recovery. However, there is some evidence of considerable stigma around psychological distress in Sierra Leone. Asare and Jones (2005) note that stigmatization affected every aspect of their work to prevent and respond to mental health problems, including attendance at clinics, compliance with medication, and particularly the availability of social support for people who are mentally ill. They report that the brief surveys they conducted showed that most of the community believed mentally ill people to be evil, violent, lazy, stupid, unable to marry or have children, and unfit to vote.

Recovery from psychological distress is a complex and multifaceted concept (Compton et al., 2020). It has an inter-subjective character, as recovery depends not only on the individual but also on other significant actors who constitute an individual's social and relational landscape (e.g. caregivers, community members) (Noiseux et al., 2010). Consequently, studying what it means to recover from distress from the perspective of these significant actors can contribute to interventions designed to reduce stigma and promote culturally responsive interpersonal and social connections (Song et al., 2013). There is evidence that the way people define conceptualize and experience recovery varies across communities (McKenzie and Bhui, 2007), and little is known about this issue in the Sierra Leone context.

As mentioned before, individuals with mental health problems face high levels of stigma in Sierra Leone (Shackman and Price, 2013; Hann et al., 2015), and communities play an important role in supporting them, given the limited capacity within the formal health care system. Therefore, understanding what are perceived to be the key signs of recovery in that context could contribute to the development of effective interventions to both prevent and respond to psychological distress.

Recovery can entail various pathways (Kerman et al., 2019; Compton et al., 2020; Pahwa et al., 2020), and community perceptions of recovery are likely to be equally complex. QCA is well-positioned to investigate these pathways, as it aims to uncover necessary or sufficient conditions that lead to the occurrence of the phenomenon of interest (Ragin, 2008; Legewie, 2013; Rubinson, 2019).

The use of QCA in health research, and other fields of science, is gradually expanding (Warren et al., 2014; Kahwati et al., 2016; McAlearney et al., 2016; Andersson and Harkness, 2018; Breuer et al., 2018; Goicolea et al., 2018), and its benefits have been widely reported. A number of studies have demonstrated that QCA facilitates identification of the factors which are most important for the production of a health outcome (Warren et al., 2014; Kahwati et al., 2016; McAlearney et al., 2016). Studies in fields such as sociology and politics have demonstrated how QCA enables understanding of a phenomenon through the exploration of multiple combinations of causal factors, as well as necessary and sufficient ones, for an outcome to occur (Cress and Snow, 2000; Stevenson and Greenberg, 2000; Fiss, 2011). However, there are relatively few examples of QCA being used in mental health 
research, with studies of mental health service provision in Sweden (Goicolea et al., 2018) and the determinants of stigma (Andersson and Harkness, 2018) being notable exceptions. No studies have used QCA to analyse perceptions of recovery from mental health problems or psychological distress. Therefore, there is a major opportunity to explore the application of QCA in mental health research.

The analysis presented in this paper addressed two research questions: (a) What are lay persons' perceptions of recovery from psychological distress in Sierra Leone? and (b) What are the implications of these perceptions for promoting mental wellbeing in the communities of Sierra Leone?

This study used QCA to analyse lay persons' perceptions of recovery from psychological distress in Sierra Leone. This provides a basis for considering the potential for use of the method to understand factors influencing stigma around mental health problems and potential strategies for promoting social inclusion.

\section{Methodology}

Data were collected in the context of a wider study of idioms of distress (Horn et al., 2020). The analysis in this paper draws on 75 case study interviews. Interviewees were selected through a convenience sample from five districts in Sierra Leone (Bo, Kailahun, Kambia, Kono and Western Area). These five districts were chosen to represent the four provinces of the country, plus the Western Area (which includes the capital city, Freetown). Fifteen interviews were conducted in each District. The total sample of 75 respondents comprised 36 men and 39 women. The ages of the interviewees ranged from 18 to 76 years, with a mean age of 42 years.

As noted above, convenience sampling was used to recruit interview participants. Interviews were conducted in places convenient for the respondents (e.g., home or community venue). Most interviews (49 of 75) were conducted in Krio, the preferred language of the respondents. For non-Krio speakers, a translator from the local area was hired by the local research team to translate during the interview. On average, interviews lasted around $40 \mathrm{~min}$.

Case study interviews involved asking the interviewee to think of two people they knew personally, both of whom had suffered from emotional distress because of difficult life experiences, such as loss of a family member, loss of property, or sickness. However, one of these people, known to the interviewee, must have recovered (Person 1), and another one must not have recovered (Person 2). The interviewee was then asked to talk about the two people in detail, focusing on the difficult life events they had experienced; how they were affected (thoughts, feelings, behaviour such as self-isolation, sadness, self-talk or self-harm); and signs that indicated that the first person had recovered (Table 1). The people affected by the psychological distress that the respondents talked about were not present at the interviews.

Qualitative comparative analysis using a crisp set analysis. The primary aim of the QCA is to explore causal complexity by looking at different pathways that can lead to an outcome. It is premised on the belief that a phenomenon is complex and can be caused by different conditions coming together in various combinations. In fact, some conditions can have an opposing effect on the outcome, depending on the combinations that they are in. Thus, QCA aims to identify necessary and sufficient conditions for the outcome to occur. A necessary condition is one that is present all the time when an outcome occurs. A sufficient condition is one that leads to the occurrence of the outcome, but is not the only condition, as there are others with the same ability to lead to the production of the outcome (Ragin, 2008; Legewie, 2013; Roig-Tierno et al., 2017; Rubinson, 2019).

Ultimately, the QCA aims to produce a solution, which is a sufficient path leading to an outcome, through Boolean minimization. In other words, conditions, the presence or absence of which do not have any impact on the occurrence of the outcome, are omitted in the process of comparing different combinations of potential factors leading to an outcome. Through such minimization, the QCA produces a pathway or several pathways that lead to the outcome (Ragin, 2008; Glaesser et al., 2009; Legewie, 2013).

Generating a truth table (a raw data matrix) is a first step in QCA (Ragin, 2008; Legewie, 2013). The truth table sorts data into different combinations of values on the causal conditions (Ragin, 2008). Each row of the truth table represents one logical combination of values. The truth table has as many rows as there are logically possible combinations of values (Ragin, 2008). Each row is assigned an output value (1 indicating the occurrence of the outcome or 0 indicating non-occurrence of the outcome) (Ragin, 2008). Thus, the truth table is a summary of both different combinations of causal conditions and their associated outcome (Ragin, 2008).

Two concepts-consistency and coverage-are important for interpreting QCA outcomes. Consistency represents the extent to which a combination of conditions leads to an outcome. Coverage refers to the proportion of cases exhibiting the combination that is being assessed. For the pathway of conditions to be accepted as one that results in the outcome, consistency should be above 0.8 . The general rule is that without high consistency, there is little value in having high coverage (Legewie, 2013; Goicolea et al., 2018).

This study used crisp set analysis due to the nature of the data to enable the data to be calibrated into binary categories: 0 (absence of the condition) and 1 (presence of the condition) (Ragin, 2008; Legewie, 2013). Subsequently, qualitative data on signs of recovery was recorded in an Excel file using binary categories of 0 (absence of the condition) and 1 (presence of the condition). The analysis included running and examining truth tables as well as subset/superset and standard analysis. Fs/QCA software was used for the analysis.

Ethics approval and consent to participate. This study was approved by the Queen Margaret University Research Ethics Committee and by the Office of the Sierra Leone Ethics and Scientific Review Committee, Ministry of Health and Sanitation. A standard information sheet about the study was read to

Table 1 Questions asked during case study interviews and number of responses gathered.

\begin{tabular}{ll} 
No. & Question \\
\hline 1 & $\begin{array}{l}\text { Difficult life event/s that led to } \\
\text { emotional distress }\end{array}$ \\
2 & Signs of distress \\
3 & Signs of recovery
\end{tabular}

\section{Responses}

150 responses were gathered from 75 interviewees (75 responses about Person 1, who recovered, and 75 responses about Person 2 , who did not recover)

150 responses were gathered from 75 interviewees (75 responses about Person 1, who recovered, and 75 responses about Person 2 , who did not recover)

75 responses were gathered focusing only on Person 1 who recovered 
respondents who gave verbal informed consent to be interviewed for the study. The field researchers documented the verbal consent of respondents. Names of case study interviewees were not recorded.

During the interviewees, questions about problems affecting people, in general, were asked. Interviewers did not ask any specific questions about the problems of the interviewees. If interviewees spoke of their individual problems or personal experiences, interviewers were instructed to redirect the discussion back to the problems of specific people who they were talking about. Even though interviewers were trained on how to respond if any of the interviewees became upset, no such case was encountered in the course of the fieldwork.

Limitations. As the decision to explore the data using QCA was made after completion of data collection, some information about the people who recovered and did not recover from psychological distress (e.g., gender, age) was not available for the QCA analysis. In future studies, the potential use of QCA for analysis should be anticipated at the time of confirming the scope of data collection.

\section{Results}

Events leading to mental distress and signs of distress. Table 2 presents the events that led to psychological distress. The events were reported both for those who recovered and those who did not. Nine categories of events were identified. Among 75 cases of recovered people, the events leading to distress were not known in 11 cases (15\%). Among the remaining 64 (85\%) cases, two events were encountered in four cases. The three most prevalent events for individuals who recovered from psychological distress were the death of their family member(s), loss of property/job/study/ status/role; and a relationship problem (Table 2 ).

Of the 75 cases of people who did not recover, the event leading to distress was unknown for four (5\%). In five cases, two events were reported. The most prevalent events leading to distress for people who did not recover are similar to those reported for individuals who recovered (Table 2). However, a significantly higher number of those who did not recover from mental distress encountered the death of their family member(s), compared to those who recovered $(p<0.05)$. Differences in the other categories were not statistically significant.

Thirty signs of distress (listed in Appendix 1, Supplementary Information) were identified (Horn et al., 2020). For the purpose of this paper, the most frequent six signs of distress were analysed. Table 3 shows that these signs were experienced both by people who recovered and by people who did not recover from psychological distress. A large difference in the percentages of the two groups can be seen with regard to the last sign in Table 3. A much higher percentage of individuals who recovered were violent and aggressive to other people than those who did not recover.
Signs of recovery from psychological distress. Thirty-eight recovery signs were identified in 75 interviews using inductive qualitative analysis. Appendix 2 (see Supplementary Information) provides a list of these recovery signs, with the frequencies of their occurrence in the data. After a careful examination of the identified signs of recovery, some of them were grouped together. The QCA analysis focused only on the six recovery signs that were frequently reported (more than 10 mentions) (Table 4).

A truth table (Appendix 3, Supplementary Information) was generated in fs/QCA and reviewed to identify prevalent conditions and pathways that lead to an outcome (Ragin, 2008; Legewie, 2013). Of 75 recovered cases, only 13 cases (17\%) had one sign of recovery, and the remaining 62 cases $(83 \%)$ had multiple signs of recovery: 26 cases (35\%) had two signs of recovery, 23 cases $(31 \%)$ had three signs, 12 cases $(16 \%)$ had four signs, and 1 case (1\%) had five signs of recovery.

Healthy relations with family, friends, and community members and work/study occur together in six cases. Healthy relations imply such activities as spending time with friends and family, communicating with others respectfully, getting involved in community activities and trying to help others (Table 4). Work/study indicates being engaged in a constructive activity such as having employment or a business, farming, or studying at school or college (Table 4). The truth table also shows that these two signs also occur together and individually in combination with other signs in a number of cases. This prompted investigation of these two signs in more depth. A truth tablecontaining only healthy relations and work/study as conditions and recovery as an outcome-was run.

Figure 1 visualizes the outcome of the truth table analysis (Rubinson, 2019). Only 7 (9\%) of the 75 cases lacked both healthy relations and work/study, while the remaining $68(91 \%)$ had at least one of these signs. Healthy relations and work/study occur together in 26 (35\%) of the 75 cases. These two signs also occur independently in 42 cases: healthy relations occur in additional 23 cases and work/study in additional 19 cases. In 33 of the 42 cases where the two signs occur independently, they are in a pattern with either one or several of the signs: faith, hope, new relations, and personal care.

Ragin (2008) indicates that the researcher should critically assess the truth table and form hypothetical combinations of factors leading to an outcome. Consequently, based on the analysis of truth tables, the following hypothetical combinations of predictive signs of recovery were deduced. QCA used Boolean algebra where a multiplication sign denotes "logical AND", and a plus sign indicates "logical OR" (Ragin, 2008).

Healthy relations and work/study lead to recovery (healthyrel*work/study)

Healthy relations and work/study and other sign/s lead to recovery (healthyrel*work/study* other sign/s)

Table 2 Events that led to psychological distress.

\section{Events that led to mental distress}

1. Death of a family member/members

2. Loss of property/job/study/status/role

3. Relationship problems (family conflict, spouse left)

4. Accident/injury/severe sickness

5. Curse/bewitched

6. Drug use

7. Deported

8. Imprisonment of oneself or family member

9. Disappointment-unable to travel abroad

Not clear

Recovered $(n=75)(\%)$

24

20

17

9

9

5

3

3

15
Non-recovered $(n=75)(\%)$

43

16

21

4

5

3

5 


\section{Table 3 Most frequent six signs of distress.}

\section{Sign of distress}

Recovered $(n=75) \quad$ Non-recovered $(n=75)$

Feeling or looked sad and unhappy; discouraged; felt disappointed

$\begin{array}{ll}35(47 \%) & 34(45 \%) \\ 37(49 \%) & 24(32 \%)\end{array}$

Stays indoors or isolates self; disconnects from people, stops going to public gatherings including mosque or church

Talking to self and/or inanimate objects (e.g. trees); sings, shouts or laughs to self

Appears dirty or untidy (including urinating or defecating on self); may eat dirty food from street or 24 (32\%)

$33(44 \%)$

dustbin; picks up dirty things

Thoughts of/ attempts suicide (e.g. drinking poison); physically harms self (e.g. pinches skin, 31 (41\%) pulls hair)

Violent or aggressive to people (stoning, fighting, beating wife, taking people's food); has thoughts of 30 (40\%)

harming or killing others (e.g. wife); destroys things (or wants to)

\section{Table 4 Most frequent six signs of recovery used in QCA analysis.}

\begin{tabular}{|c|c|c|c|}
\hline Code & Code description & $\begin{array}{l}\text { Recovery signs from the inductive analysis constituting } \\
\text { the code }\end{array}$ & Frequency \\
\hline healthyrel & $\begin{array}{l}\text { Having healthy relationships with family, friends, and } \\
\text { community members }\end{array}$ & $\begin{array}{l}\text { - Spends time with friends/family/socializing } \\
\text { - Communicates in normal way/good way } \\
\text { - Good relationships with others } \\
\text { - Involved in community activity (e.g. women's } \\
\text { organization)/gatherings } \\
\text { - Treats others respectfully/non-abusively } \\
\text { - Tries to help others } \\
\text { - Opens up/shares problems with people }\end{array}$ & 49 \\
\hline work/study & Being engaged in a constructive activity (work or study) & $\begin{array}{l}\text { - Got job/started business/farming/gone back to school or } \\
\text { college } \\
\text { - Actively involved in or concentrating on work/school/other } \\
\text { activities }\end{array}$ & 45 \\
\hline percare & Taking care of oneself & $\begin{array}{l}\text { - Dresses well/good personal hygiene } \\
\text { - Stopped drinking/smoking/drug use/gambling } \\
\text { - Eating well (good appetite) } \\
\text { - Does enjoyable activities (e.g. listens to music/walks } \\
\text { on beach) } \\
\text { - Takes medication as prescribed } \\
\text { - Avoiding negative friends }\end{array}$ & 30 \\
\hline faith & $\begin{array}{l}\text { Having religious beliefs and/or engaging in faith-related } \\
\text { practices }\end{array}$ & $\begin{array}{l}\text { - Goes for prayers/to church/mosque } \\
\text { - Grateful/thankful to God }\end{array}$ & 25 \\
\hline newrel & Building new relationships (e.g. getting married) & - Started new relationship (partner/spouse) & 21 \\
\hline hope & Having hopes/plans/positive beliefs for future & $\begin{array}{l}\text { - Hope that life will improve } \\
\text { - Makes decisions about how to move forward/plans } \\
\text { for future } \\
\text { - Believes that there is still some good in life/all is not lost/ } \\
\text { has courage. }\end{array}$ & 17 \\
\hline
\end{tabular}

Healthy relations or work/study and other sign/s lead to recovery (healthyrel + work/study*other sign/s)

Outcomes of subset/superset analysis showed that healthy relations and work/study had the consistency of 1 and coverage of 0.65 and 0.60 , respectively, suggesting that they may be considered necessary conditions (Table 5).

The solution produced by the standard analysis (Table 6) indicates that either healthy relations or work/study is present in the first five pathways with raw coverage above 0.20 ; while other signs (i.e., faith, hope, newrel, percare) are absent. In three pathways, healthy relations and work/study are in combination with one of the other signs (work/study*faith; healthyrel*percare; healthyre ${ }^{*}$ faith). Only in two pathways with low raw coverage are healthy relations and work/study absent. Drawing on this, healthy relations and work/study can be considered sufficient but not necessary for someone to be considered to have recovered from psychological distress. Put differently, the presence of one of these (healthyrel + work/study) is a sufficient predictive factor of recovery from distress.

\section{Discussion}

QCA provided a novel avenue for exploring data by transforming qualitative data into a quantitative format and looking at the patterns of conditions leading to an outcome (Ragin, 2008; Legewie, 2013). The truth table enabled us to examine which signs and combinations of signs were prevalent (Ragin, 2008; Legewie, 2013) and to visualize data in a diagram for more indepth exploration of data (Rubinson, 2019). Importantly, QCA enabled us to determine which signs of recovery are sufficient for one to be considered likely to recover from psychological distress (McAlearney et al., 2016; Rubinson, 2019).

This study contributes to the literature on recovery from psychological distress, which has mostly focused on recovery from the perspective of high-income countries (Piat et al., 2009; Noiseux et al., 2010; Buchanan et al., 2014; Jacob, 2015; Tremblay et al., 2017). In contrast, this study presented community members' perception of recovery in the fragile setting of Sierra Leone. Two signs (work/study and healthy rel) were identified as sufficient signs for a person to be considered likely to recover from distress in the context of Sierra Leone. Engaging in a constructive 


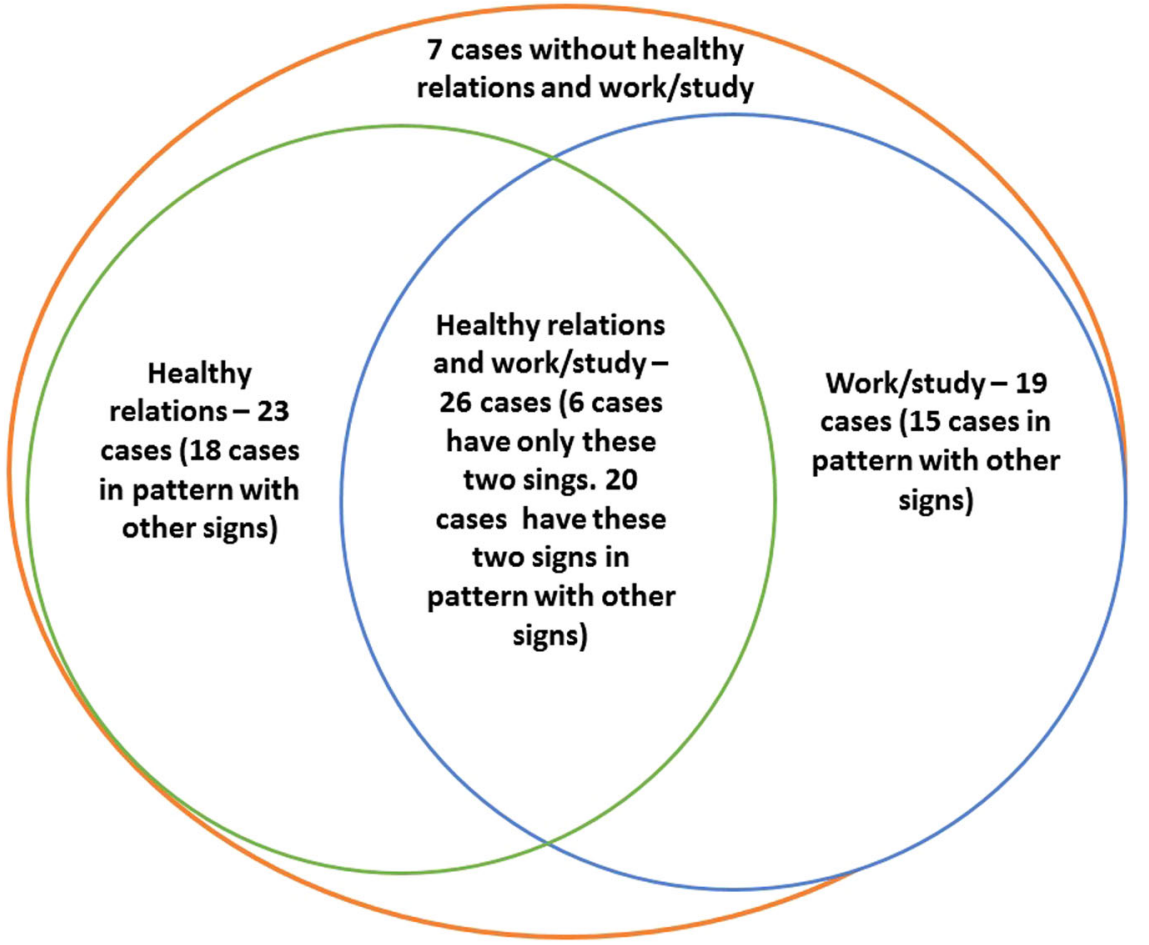

Fig. 1 Venn diagram visualizing the outcomes of the truth table analysis containing healthy relations and work/study as conditions and recovery as an outcome. A green circle shows the number of cases with healthy relations (healthyrel). A blue circle shows the number of cases with work/study. The intersection of the green and blue circles shows the number of cases with both healthy relations and work/study. An orange circle shows the number of cases with neither healthy relations and work/study.

Table 5 Outcomes of the subset/superset analysis.

\begin{tabular}{llll} 
Terms & Consistency & coverage & combined \\
\hline Healthyrel & 1 & 0.653333 & 0.804239 \\
work/study & 1 & 0.600000 & 0.770714 \\
Percare & 1 & 0.400000 & 0.629285 \\
healthyrel*work/study & 1 & 0.346667 & 0.585833 \\
Faith & 1 & 0.333333 & 0.574456 \\
Newrel & 1 & 0.280000 & 0.526498 \\
healthyrel*percare & 1 & 0.266667 & 0.513809 \\
Hope & 1 & 0.226667 & 0.473709 \\
work/study*faith & 1 & 0.213333 & 0.459565 \\
healthyrel*faith & 1 & 0.200000 & 0.444972 \\
\hline Conditions and their patterns with coverage above 0.20 are reported in the table.
\end{tabular}

activity such as work or study or having healthy relationships with family, friends and wider community members are perceived to be two alternative indications that a person is recovering.

It is important to note that the salience of these two factors relates to the Sierra Leone cultural context in ways which are not fully explored in this study. There are high levels of unemployment and poverty in the country (United Nations Development Programme, 2019) and jobs are commonly in the informal sector, especially for young people. This means that continuing with constructive activity requires considerable motivation, especially when the income generated is small. A failure to continue with these activities (work, study, farming, business) was identified as a common sign of psychological distress in another phase of this project (Horn et al., 2020), which suggests that a person's engagement in work and other forms of constructive activity is not seen purely as a reflection of the economic situation in the country, but rather as an indicator of the individual's emotional wellbeing. In the same study, withdrawing from people ('stays indoors or isolates self; disconnects from people, stops going to public gatherings including mosque or church') was also identified as a key sign of psychological distress. Whilst a range of other signs of distress were identified in the earlier stage of our study, the findings of this analysis suggests that a return to engagement in constructive activity, and a reconnection with people, are particularly salient signs of recovery in this context.

Our findings have implications for promoting recovery in Sierra Leone, where mental health services and resources are limited.

The first practical implication of these findings is their potential contribution to anti-stigma campaigns in the country. As previously discussed, people with mental health problems in Sierra Leone are highly stigmatized, and there is some research evidence to support this (Asare and Jones, 2005; WHO, 2012). Community-based organizations in the country, such as the Mental Health Coalition-Sierra Leone, are making exceptional efforts to address this issue, and people with lived experience of mental health problems play a significant role in these activities. In order to challenge the currently held belief that people with mental illness are unlikely to recover, this literature helps to demonstrate that people experiencing psychological distress are still able to develop healthy relationships and contribute to their communities with appropriate support.

The second practical implication relates to the importance of social inclusion in the recovery process of people experiencing psychological distress (Cobigo and Stuart, 2010; Burgess and Campbell, 2014; Singh et al., 2016; Hall et al., 2019). In a country like Sierra Leone, which has very limited formal mental health capacity, family and community members play a particularly crucial role in supporting those with mental health problems. In practice, the majority of those experiencing psychological distress will receive support from within their communities, from 


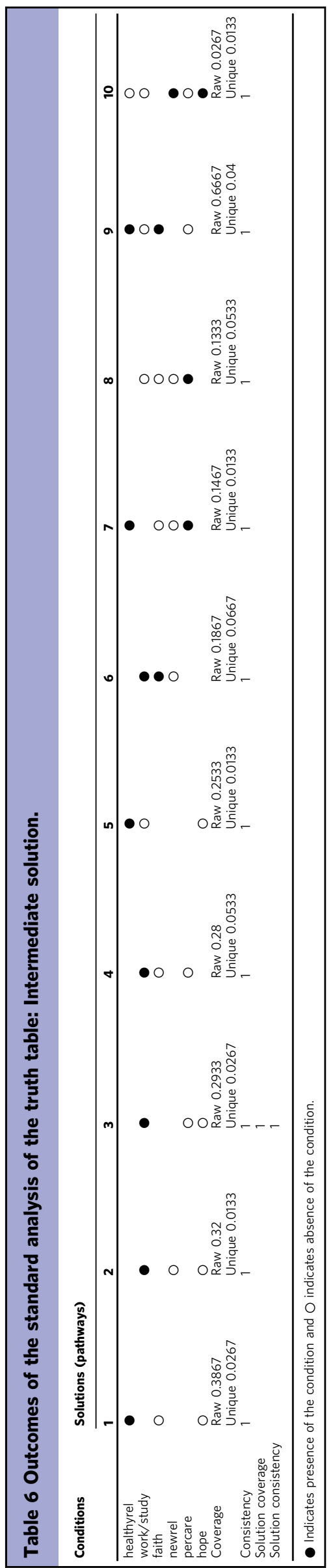

non-specialists including community leaders, religious leaders, family and friends. The development of mental health competence in communities-which has such a positive impact on recovery as described by Mathias and colleagues (Mathias, 2016; Mathias et al., 2018)-requires mental health advocates and practitioners to address the issues that concern affected individuals and their families. It is necessary to understand existing beliefs, including those about recovery, in order to challenge misunderstandings and move towards a deeper understanding of mental health and mental illness within the community.

Thirdly, practical interventions which focus on strengthening family and community relationships and enabling people with mental health problems to access education and employment opportunities have already been shown to have positive effects on mental health (Lund et al., 2011; Petersen et al., 2016; Chen et al., 2019; Drosos and Theodoroulakis, 2019; Hall et al., 2019). These findings suggest that they are likely to have an added benefit of strengthening social inclusion, as family and community members perceive these as signs that the person is recovering, leading to greater acceptance.

The findings of this study, along with the other research discussed above, support the concept that strengthening mental health is about more than a reduction in painful thoughts and feelings. Equally important factors are a good quality of life, reflected in social relationships and constructive activity.

\section{Conclusion}

This paper makes a contribution in two ways. Firstly, the paper shows that the QCA method can be of high relevance and use in mental health research. The method can help unpack predictive factors of recovery from psychological distress. Secondly, the paper demonstrates that community members in Sierra Leone perceive someone to recover from distress when they engage in a constructive activity such as work or study, as well as have healthy relationships with family, friends, and community members. These two signs emerged in the QCA analysis as sufficient for one to be considered to have recovered from psychological distress, suggesting that there is a need for community-based interventions that would involve people with mental health issues in constructive activity and provide them with social support. This advances our understanding of recovery from psychological distress and greatly contributes to the limited literature on recovery, especially in the context of fragile settings.

\section{Data availability}

The data that support the findings of this study are available from the corresponding author on reasonable request.

Received: 21 October 2020; Accepted: 21 June 2021; Published online: 07 July 2021

\section{References}

Andersson MA, Harkness SK (2018) When do biological attributions of mental illness reduce stigma? Using qualitative comparative analysis to contextualize attributions. Soc Ment Health 8(3):175-194. https://doi.org/10.1177/ 2156869317733514

Asare J, Jones L (2005) Tackling mental health in Sierra Leone. BMJ (Clin Res ed) 331(7519):720. https://doi.org/10.1136/bmj.331.7519.720-b

Betancourt TS et al. (2011) Sierra Leone's child soldiers: war exposures and mental health problems by gender. J Adolesc Health 49(1):21-28. https://doi.org/ 10.1016/j.jadohealth.2010.09.021

Betancourt TS et al. (2013) Post-traumatic stress symptoms among former child soldiers in Sierra Leone: follow-up study. Br J Psychiatry 203(3):196-202. https://doi.org/10.1192/bjp.bp.112.113514 
Breuer E et al. (2018) Using qualitative comparative analysis and theory of change to unravel the effects of a mental health intervention on service utilisation in Nepal. BMJ Glob Health 3(6):1-11. https://doi.org/10.1136/bmjgh-2018001023

Buchanan A, Peterson S, Falkmer T (2014) A qualitative exploration of the recovery experiences of consumers who had undertaken shared management, person-centred and self-directed services. Int J Ment Health Syst 8(1):8-10. https://doi.org/10.1186/1752-4458-8-23

Burgess R, Campbell C (2014) Contextualising women's mental distress and coping strategies in the time of AIDS: a rural South African case study. Transcult Psychiatry 51(6):875-903. https://doi.org/10.1177/1363461514526925

Chen X, Wang T, Busch S (2019) Does money relieve depression? Evidence from social pension expansions in China | IZA-Institute of Labor Economics. Soc Sci Med 220:411-420. https://www.iza.org/publications/dp/10037/doesmoney-relieve-depression-evidence-from-social-pension-expansions-inchina https://www.iza.org/publications/dp/10037/does-money-relievedepression-evidence-from-social-pension-expansions-in-china

Cobigo V, Stuart H (2010) Social inclusion and mental health. Curr Opin Psychiatry 23(5):453-457. https://doi.org/10.1097/YCO.0b013e32833bb305

Compton MT et al. (2020) Associations between two domains of social adversity and recovery among persons with serious mental illnesses being treated in community mental health centers. Community Mental Health J 56(1):22-31. https://doi.org/10.1007/s10597-019-00462-0

Cress DM, Snow DA (2000) 'The outcomes of homeless mobilization: the influence of organization, disruption, political mediation, and framing'. Am J Sociol 10 (4):1063-1104. https://doi.org/10.1086/210399

Dinos S et al. (2004) Stigma: the feelings and experiences of 46 people with mental illness-qualitative study. Br J Psychiatry 184:176-181. https://doi.org/ 10.1192/bjp.184.2.176

Drosos N, Theodoroulakis M (2019) Employment as an integral part of social inclusion: the case of mental health patients in greece. Int Perspect Incl Educ 13:221-237. https://doi.org/10.1108/S1479-363620190000013017

Fiss PC (2011) Building better causal theories: a fuzzy set approach to typologies in organization research. Acad Manag J 54(2):393-420. https://doi.org/10.5465/ AMJ.2011.60263120

Glaesser J et al. (2009) Underlying success in open-ended investigations in science: using qualitative comparative analysis to identify necessary and sufficient conditions. Res Sci Technol Educ 27(1):5-30. https://doi.org/10.1080/ 02635140802658784

Goicolea I et al. (2018) Accessibility and factors associated with utilization of mental health services in youth health centers. A qualitative comparative analysis in northern Sweden. Int J Ment Health Syst 12(1):1-9. https://doi. org/10.1186/s13033-018-0249-4

Gupta L, Zimmer C (2008) Psychosocial intervention for war-affected children in Sierra Leone. Br J Psychiatry 192(3):212-216. https://doi.org/10.1192/bjp. bp.107.038182

Hall $\mathrm{T}$ et al. (2019) Social inclusion and exclusion of people with mental illness in Timor-Leste: a qualitative investigation with multiple stakeholders. BMC Public Health 19(1):1-13. https://doi.org/10.1186/s12889-019-7042-4

Hann $\mathrm{K}$ et al. (2015) Factors for success in mental health advocacy. Glob Health Action 8. https://doi.org/10.3402/gha.v8.28791.

Harris D et al. (2018) Mental health nurses and disaster response in Sierra Leone. Lancet Glob Health 6(2):e146-e147. https://doi.org/10.1016/S2214-109X(17) 30492-8

Harris D et al. (2020) Mental health in Sierra Leone. BJPsych Int 17(1):14-16. https://doi.org/10.1192/bji.2019.17

Horn R et al. (2020) Expressions of psychological distress in Sierra Leone: implications for community-based prevention and response. Global Mental Health 7:e19. https://doi.org/10.1017/gmh.2020.12

Jacob K (2015) Recovery model of mental illness: a complementary approach to psychiatric care. Indian J Psychol Med 37(2):117-118. https://www.ncbi.nlm. nih.gov/pmc/articles/PMC4418239/\#_ffn_sectitle https://www.ncbi.nlm.nih. gov/pmc/articles/PMC4418239/\#_ffn_sectitle

Kahwati L et al. (2016) Using qualitative comparative analysis in a systematic review of a complex intervention. Syst Rev 5(1):1-12. https://doi.org/10.1186/ s13643-016-0256-y

Kerman N et al. (2019) Predictors of mental health recovery in homeless ddults with mental illness. Community Mental Health J 55(4):631-640. https://doi. org/10.1007/s10597-018-0356-3

Kirmayer LJ, Pedersen D (2014) Toward a new architecture for global mental health. Transcult psychiatry 51(6):759-76. https://doi.org/10.1177/ 1363461514557202

Lee-Kwan SH et al. (2014) Support services for survivors of ebola virus diseaseSierra Leone, 2014. Morb Mortal Wkly Rep 63(50):1205-1206

Legewie N (2013) An introduction to applied data analysis with qualitative comparative analysis. Forum Qual Soc Res/Forum Qual Sozialforsch 14(3):45. https://doi.org/10.17169/fqs-14.3.1961
Lund C, De Silva M, Plagerson S, Cooper S, Chisholm D, Das J et al. (2011) Poverty and mental disorders: breaking the cycle in low income and middle income countries. Lancet 378(9801):1502-1514

Mathias K (2016) Shadows and light: examining community mental health competence in North India. Umeä University. http://www.diva-portal.org/smash/ record.jsf?pid=diva2\%3A1044412\&dswid=-1479. Accessed 14 Aug 2020.

Mathias K et al. (2018) Strengthening community mental health competence-a realist informed case study from Dehradun, North India. Health Soc Care Community 26(1):e179-e190. https://doi.org/10.1111/hsc.12498

McAlearney AS et al. (2016) Using qualitative comparative analysis of key informant interviews in health services research: enhancing a study of adjuvant therapy use in breast cancer care. Med care 54(4):400-5. https://doi.org/ 10.1097/MLR.0000000000000503

McKenzie K, Bhui K (2007) Institutional racism in mental health care. Br Med J. 649-650. https://doi.org/10.1136/bmj.39163.395972.80.

McPake B, Dayal P, Herbst CH (2019) Never again? Challenges in transforming the health workforce landscape in post-Ebola West Africa. Hum Resour Health 17(1):19. https://doi.org/10.1186/s12960-019-0351-y

Miller KE, Rasmussen A (2014) War experiences, daily stressors and mental health five years on. Intervention 12:33-42. https://doi.org/10.1097/ wtf.0000000000000066

Newnham EA et al. (2015) Youth mental health after civil war: the importance of daily stressors. Br J Psychiatry 206(2):116-121. https://doi.org/10.1192/bjp. bp.114.146324

Noiseux S et al. (2010) The process of recovery of people with mental illness: the perspectives of patients, family members and care providers: Part 1 . BMC Health Serv Res 10. https://doi.org/10.1186/1472-6963-10-161.

Onken SJ et al. (2007) An analysis of the definitions and elements of recovery: a review of the literature. Psychiatr Rehabil J 31(1):9-22. https://doi.org/ 10.2975/31.1.2007.9.22

Pahwa R et al. (2020) Social networks, community integration and recovery for individuals with severe mental illnesses in India and the U.S: a comparative study. Community Mental Health J (0123456789). https://doi.org/10.1007/ s10597-019-00546-x.

Patel V et al. (2018a) The Lancet Commission on global mental health and sustainable development. Lancet 392(10157):1553-1598. https://doi.org/10.1016/ S0140-6736(18)31612-X

Patel V et al. (2018b) The Lancet Commission on global mental health and sustainable development. Lancet 1553-1598. https://doi.org/10.1016/S0140-6736 (18)31612-X.

Patel V, Prince M (2010) Global mental health: a new global health field comes of age. J Am Med Assoc. 1976-1977. https://doi.org/10.1001/jama.2010.616.

Petersen I et al. (2016) Promotion, prevention and protection: Interventions at the population- and community-levels for mental, neurological and substance use disorders in low- and middle-income countries. Int J Mental Health Syst 10(1):1-13. https://doi.org/10.1186/s13033-016-0060-z

Piat $\mathrm{M}$ et al. (2009) What does recovery mean for me? Perspectives of Canadian mental health consumers. Psychiatr Rehabil J 32(3):199-207. https://doi.org/ 10.2975/32.3.2009.199.207

Ragin C (2008) User's guide: Fuzzy set/qualitative comparative analysis. http:// www.socsci.uci.edu/ cragin/fsQCA/download/fsQCAManual.pdf. Accessed 14 May 2019.

Roig-Tierno N, Gonzalez-Cruz TF, Llopis-Martinez J (2017) An overview of qualitative comparative analysis: a bibliometric analysis. J Innov Knowl 2 (1):15-23. https://doi.org/10.1016/j.jik.2016.12.002

Rubinson C (2019) Presenting qualitative comparative analysis: notation, tabular layout, and visualization. Methodol Innov 12(2):205979911986211. https:// doi.org/10.1177/2059799119862110

Scott JT et al. (2016) Post-ebola syndrome, Sierra Leone. Emerg Infect Dis 22 (4):641-646. https://doi.org/10.32032/eid2204.151302

Shackman J, Price BK (2013) Mental health capacity building in northern Sierra Leone. Intervention 11(3):261-275. https://doi.org/10.1097/ wtf.0000000000000010

Sierra Leone Statistics (2016) Statistics Sierra Leone: population and housing census. http://www.statistics.sl. Accessed 5 May 2020.

Singh L, Singh PK, Arokiasamy P (2016) Social network and mental health among older adults in rural Uttar Pradesh, India: a cross-sectional study. J CrossCult Gerontol 31(2):173-192. https://doi.org/10.1007/s10823-016-9286-0

Song SJ, Van Den Brink H, De Jong J (2013) Who cares for former child soldiers? Mental health systems of care in sierra leone. Community Mental Health J 49 (5):615-624. https://doi.org/10.1007/s10597-013-9597-3

Sorensen CW et al. (2017) Integrating mental health in primary healthcare in lowincome countries: changing the future for people with mental disorders. Nord J Psychiatry 71:151-157. https://doi.org/10.1080/08039488.2016.1245784

Stevenson WB, Greenberg D (2000) Agency and social networks: strategies of action in a social structure of position, opposition, and opportunity. Adm Sci Q 45(4):651-678. https://doi.org/10.2307/2667015 
Stewart C et al. (2016) A preliminary evaluation of Acceptance and Commitment Therapy (ACT) training in Sierra Leone. J Context Behav Sci 5(1):16-22. https://doi.org/10.1016/j.jcbs.2016.01.001

Thornicroft G (2013) Shunned: discrimination against people with mental illness, Shunned. Oxford University Press.

Tremblay C, Coulombe V, Briand C (2017) Users' involvement in mental health services: programme logic model of an innovative initiative in integrated care. Int J Mental Health Syst 11(1):1-10. https://doi.org/10.1186/s13033-0160111-5

United Nations Development Programme (2019) Briefing note for countries on the 2020 Human Development Report. http://hdr.undp.org/en/data. Accessed 11 May 2021.

Warren J, Wistow J, Bambra C (2014) Applying qualitative comparative analysis (QCA) in public health: a case study of a health improvement service for long-term incapacity benefit recipients. J Public Health 36(1):126-133. https://doi.org/10.1093/pubmed/fdt047

WHO (2012) WHO proMIND: profiles on mental health in development. http:// www.who.int/mental_health/policy/country/countrysummary/en/index.html. Accessed 1 Jul 2020

World Bank (2019) Sierra Leone overview. https://www.worldbank.org/en/country/ sierraleone/overview\#1. Accessed 5 May 2020.

Yadav S, Rawal G (2015) The current mental health status of ebola survivors in Western Africa. J Clin Diagn Res 9(10):LA01-LA02. https://doi.org/10.7860/ JCDR/2015/15127.6559

\section{Acknowledgements}

The authors thank Elizabeth Taylor (COMAHS) and the field researchers who were involved in the data collection: Amjata Bayoh, Angella S. Summia, Emmanuel Alpha, Hassan Milton Conteh, Isatu A. Conteh, Joan B. Lavally, Jonathan Nyuma, Mamadu Jalloh, Simeon S. Sesay, Sylvanus Aitkins and Tenneh Millicent Conteh. The authors also thank Professor Sophie Witter for commenting on early drafts of the manuscript. This study was funded by grant 16/136/100 from the National Institute for Health Research (NIHR) to the NIHR Global Health Research Unit on Health in Situations of Fragility.
The views expressed are those of the authors and not necessarily those of the NIHR or the Department of Health and Social Care.

\section{Competing interests}

The authors declare no competing interests.

\section{Additional information}

Supplementary information The online version contains supplementary material available at https://doi.org/10.1057/s41599-021-00845-3.

Correspondence and requests for materials should be addressed to K.J.

Reprints and permission information is available at http://www.nature.com/reprints

Publisher's note Springer Nature remains neutral with regard to jurisdictional claims in published maps and institutional affiliations.

cc (i) Open Access This article is licensed under a Creative Commons Attribution 4.0 International License, which permits use, sharing, adaptation, distribution and reproduction in any medium or format, as long as you give appropriate credit to the original author(s) and the source, provide a link to the Creative Commons license, and indicate if changes were made. The images or other third party material in this article are included in the article's Creative Commons license, unless indicated otherwise in a credit line to the material. If material is not included in the article's Creative Commons license and your intended use is not permitted by statutory regulation or exceeds the permitted use, you will need to obtain permission directly from the copyright holder. To view a copy of this license, visit http://creativecommons.org/ licenses/by/4.0/.

(C) The Author(s) 2021 